\title{
Galvani's Spark: the story of the nerve impulse
}

\author{
Alan J. Mc Comas. ISBN 978-0-19-975175-4. \\ One volume $(16 \times 23 \mathrm{~cm})$ with 391 pages. New York, 2011. \\ Oxford University Press (198 Madison Avenue, 10016 New York, USA).
}

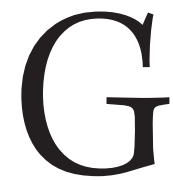

alvani's Spark: the Story of the Nerve Impulse is a detailed and thoughtful account of research into the nature of the nerve impulse, the electrochemical signal that enables the various parts of the nervous system to communicate with each other and which, ultimately, is responsible for all our thoughts, words and deeds. Starting with the seminal observation of Galvani (c. 1770), that a spark from a friction machine caused a frog's leg to contract, the book covers all the relevant research in the next two and half centuries, culminating in the definitive X-ray diffraction studies of voltage-gated ion channels by Roderick MacKinnon. Along the way, through 23 chapters, the book embraces the work of many physiologists, biologists, physicians, biochemists and physicists, with special attention being given to the voltage-clamp experiments of Hodgkin and Huxley in the early 1950s; the book is itself dedicated to Sir Andrew Huxley, now in his $95^{\text {th }}$ year. The account is enriched by details of the lives of those involved in the research, and by the doubts and controversies, which were inevitable in a task of this magnitude.

McComas, currently Emeritus Professor at McMaster University, Canada, is well equipped to write the story; a neurophysiologist himself, he is best known for estimating numbers of spinal motor neurons in human subjects, including those with neuromuscular disorders.

It is likely that Galvani's spark will become a classic and will be read with interest by many established researchers and physicians involved with the nervous system. For those entering the field it provides a valuable and unique introduction to the subject.

Roberto E. Sica 